\title{
A Comparative Evaluation for Detection of Hepatitis B Surface Antigen and Anti HCV Antibodies by Rapid Diagnostic Tests and ELISA Method at Govt. Medical College, Dungarpur, India
}

\author{
Bhupendra Kumar Mandawat" and Vipul Mathur
}

Department of Microbiology, Government Medical College, Dungarpur(Rajasthan), India

*Corresponding author

\section{A B S T R A C T}

Hepatitis B virus and hepatitis $\mathrm{C}$ virus share common modes of transmission i.e. by blood and blood products mainly and also noticed in drug addicts. Hepatitis B virus and Hepatitis $\mathrm{C}$ virus have been recognized as a major pathogen causing significant morbidity and mortality throughout the world including India. The most important markers for HBV and $\mathrm{HCV}$ infection are HBsAg and Anti HCV antibodies respectively. Detection of infection markers for these agents is a major challenge in a resource poor setting.For proper

Keywords

$\mathrm{HBV}, \mathrm{HCV}$, HBsAg, Anti HCV antibodies, Rapid test, ELISA

Article Info

Accepted: 15 June 2019 Available Online: 10 July 2019 diagnosis of infection as well as disease management and prevention, identification of appropriate test kit is necessary. The aims of this study were to compare Rapid tests with ELISA for Hepatitis B and Hepatitis $\mathrm{C}$ virus infection. The ultimate goal of this study was to recommend most reliable and cost-effective rapid card test for the diagnosis of HBV and $\mathrm{HCV}$ in areas where advance diagnostic facilities are not available. The present study was conducted in the clinical microbiology laboratory of Govt, Medical College, Dungarpur from period of $1^{\text {st }}$ March, 2019 to $15^{\text {th }}$ May2019 to comparative evaluate the detection of HBsAg and Anti HCV antibodies by rapid diagnostic tests and ELISA method. In our study, total no. of 1756samples were tested for HBsAg and 188 samples for HCV by ELISA method (gold standard) as a confirmatory methodand samples found reactive were again tested by rapid test kits. On testing for 1756 samples of $\mathrm{HBsAg}, 78$ samples were reactive by ELISA but only 70 were reactive in Rapid tests and Out of 188 samples for HCV, 7 were reactive for Anti HCV antibodies by ELISA but only6 samples were reactive by Rapid tests. For proper diagnosis of infection as well as disease management and prevention, identification of appropriate test kit is necessary. The card test's sensitivity and specificity is comparable with ELISA. These rapid kits are cheaper and easy to perform and their use should be encouraged at rural settings. ELISA is much more sensitive than rapid tests for screening of infections like HBsAg and HCV.

\section{Introduction}

The Viral Hepatitis caused by Hepatitis B Virus is termed as "Serum Hepatitis". 1-5\% infected people act as chronic carriers of HBV Virus. Major part of the chronic carriers secretes hepatitis B surface antigen (HBsAg) into blood and other secretions of the body like saliva and vaginal fluid. These chronic carriers are potentially infectious to other seronegative people. HBsAg has been accepted as a universal and the most reliable 
seromarker in case of acute HBV infection due to its appearance almost 2-4 weeks. Within HBVs, antigenic diversity is recognized in the surface antigens. HBsAg particles contain common "a" antigen, linked to two sets of mutually exclusive determinants, "d" or " $y$ " and "w" or "r" giving the four main types-adw, adr, ayw and ayr. (19, 20, 22) Hepatitis C Virus was identified in 1989 as the main aetiologicalagent of nonA, non-B hepatitis (NANBH) accounting for greater than $90 \%$ of post-transfusion hepatitis cases. It is considered to be the major cause of acute chronic hepatitis, liver cirrhosis and hepatocellular carcinoma throughout the world. It is therefore necessary to correctly diagnose Hepatitis $\mathrm{C}$ infection. The test for antibodies to $\mathrm{HCV}$ was proved to be highly valuable in the diagnosis and study of the infection, especially in the early diagnosis of $\mathrm{HCV}$ after transfusion. The diagnosis of hepatitis $\mathrm{C}$ can be easily made by finding anti$\mathrm{HCV}$ in serum/plasma. $(3,5,16,17)$ Conventional ELISA is regarded as the most commonly used screening technique for general population in Tertiary Care Hospitals of India, but due to limitations of ELISA tests like high costs, unavailability in many laboratoryand testing sites, involvement of costly instruments, time taking nature and requirement of highly skilled personnel for interpretation, rapid tests that are user friendly are gaining more importance and warrants comparison of performance. (11) Rapid diagnostic kits are a good choice as they are less expensive and do not need high technical manpower or infrastructure. (14) Were intended for field survey diagnosis, emergency and home testing. The rapid card test is known to have less sensitivity and specificity than EIA but some have sensitivity and specificity comparable to EIA (2). The ultimate goal of this study was to recommend most reliable and cost-effective rapid card test for the diagnosis of $\mathrm{HBV}$ and $\mathrm{HCV}$ in areas where advance diagnostic facilities are not available. The present study was conducted to compare the efficacy of ELISA test kits and Rapid test kits for screening in rural area and general population of India.

The present study was conducted to compare the efficacy of ELISA test kits and Rapid test kits for screeningHepatitis B and Hepatitis C infection. The present study was designed to check the sensitivity and specificity of rapid card test of HBsAg which are frequently used in different laboratories and hospitals and to compare with already confirmed cases on ELISA. The ultimate goal of this study was to recommend most reliable and cost-effective rapid card test for the diagnosis of $\mathrm{HBV}$ and $\mathrm{HCV}$ in areas where advance diagnostic facilities are not available. This study was conducted to aid in early detection and treatment of HBV and $\mathrm{HCV}$ infections and its prevention in community.

\section{Materials and Methods}

The present study was conducted in the clinical microbiology laboratory of Govt, Medical College, Dungarpur from period of $1^{\text {st }}$ March, 2019 to $15^{\text {th }}$ May 2019 to comparative evaluate the detection of HBsAg and Anti $\mathrm{HCV}$ antibodies by rapid diagnostic tests and ELISA method. A total of 1944 blood samples were collected from the outdoor and indoor patients of Govt, Medical College, Dungarpur and its allied hospitals. Out of these, total no. of 1756 samples were tested for HBsAg and 188 samples for HCV by ELISA method (gold standard) as a confirmatory method and samples found reactive were again tested by rapid test kits. The results of the reactive sample by ELISA were compared with the rapid tests. The collected blood was allowed to clot \& serum was separated. The sample were stored at $2-8^{0} \mathrm{c} \&$ tested within 7 days of collection. Patients' serum samples were subjected to following tests for detection of Anti-HCV antibodies. 
Rapid test (also called RDT or Rapid Diagnostic test, ICT or Immuno chromatographic Test)

LINE immunoassay for detection of HBsAg.

DOT immunoassay for detection of Anti-HCV antibodies.

\section{ELISA test}

For Detection of HBsAg for Detection of Anti-HCV antibodies.

For Detection of Anti-HCV antibodies.

\section{Hepalisa Ultra Test}

This is a $4^{\text {th }}$ generation micro well ELISA test for the detection of hepatitis B surface antigen (HBsAg) in Human Serum / Plasma. HBsAg has been accepted as a universal and the most reliable seromarker in case of acute $\mathrm{HBV}$ infection $[12,14]$. This Kit is manufactures by J. Mitra\& Co. Pvt. Ltd. New Delhi, India.

Principle: 4th Generation Hepalisa Ultra is a solid phase enzyme linked immunosorbent assay (ELISA) based on the "Direct Sandwich" principle. The microwells are coated with Monoclonal antibodies with high reactivity for $\mathrm{HBsAg}$.The samples are added in the wells, followed by standard procedure.

The intensity of developed blue colour is proportional to the concentration of $\mathrm{HBsAg}$ in sample. To limit the enzyme-substrate reaction, stop solution is added and a yellow colour develops which is finally read at 450 $\mathrm{nm}$ spectrophotometrically. Test procedure \& results were interpreted as per the manufacture's guidelines. Sample were interpreted as reactive for $\mathrm{HBsAg}$ (HBsAg positive) or non-reactive for HBsAg (HBsAg negative). Sample found to be reactive initially by HEPALISA ULTRAtest were again tested by visual rapid test which is HEPACARD test.

\section{Hepacard}

The $3^{\text {rd }}$ Generation HEPACARD is a rapid, visual, sensitive and qualitative in vitro diagnostic test for the detection of Hepatitis B Surface Antigen (HBsAg) in Human Serum or Plasma. The principal antigenic determinant is "a" which is common to all HBV serotypes. In addition, two pairs of sub specific determinants have been identified, d/y \& w/r, which are apparently mutually exclusive. Four antigenic combinations are therefore possible: adw, adr, ayw and ayr.This Kit is manufactures by J. Mitra \& Co. Pvt. Ltd. New Delhi, India. Principle:- HEPACARD is a one step immunoassay based on the antigen capture, or "sandwich" principle. The method uses monoclonal antibodies conjugated to colloidal gold and polyclonal antibodies immobilized on a nitrocellulose strip in a thin line. The test sample is introduced to and flows laterally through an absorbent pad where it mixes with the signal reagent. If the sample contains HBsAg and test is performed correctly, this will result in the formation of a pink band upon contact with the conjugate. Interpretation: - Results are noted as per manufactures guidelines and results were interpreted accordingly. Appearance of pink coloured line, one each in test region "T" and control region " $\mathrm{C}$ " indicates that the sample is REACTIVE for HBsAg.

\section{HCV Micro ELISA test}

The $3^{\text {rd }}$ generation HCV Microlisa is an in vitro qualitative enzyme linked immunosorbent assay for the detection of antibodies against $\mathrm{HCV}$ (anti-HCVs) in human serum or plasma. This kit is manufactured by J. Mitra\& co. Pvt. Ltd. New Delhi, India. Principle: The $3^{\text {rd }}$ generation HCV Microlisa is based on a highly sensitive 
technique, Enzyme Linked Immunosorbent Assay which detects antibodies against $\mathrm{HCV}$ in human serum and plasma. The $3^{\text {rd }}$ generation HCV Microlisa utilizes a combination of antigen with the sequence of both HCV structural and non-structural antigen i.e. CORE, E1, E2, NS3, NS4 and NS5.The results were read on Microplate spectrophotometer at $450 \mathrm{~nm}$. Cut off value was calculated as per the manufacturer's guidance and the results were interpreted accordingly. Cut off value $=0.1 \times P C x+0.1$, $\mathrm{PCX}=$ Mean absorbance of positive control Interpretation:- According to their absorbance values, samples were interpreted as either reactive for $\mathrm{HCV}$ antibody ( $\mathrm{HCV}$ positive) or non-reactive for $\mathrm{HCV}$ antibody (HCV negative) if test specimens with absorbance value within $10 \%$ below the cutoff should be considered suspect for the presence of antibodies and should be retested in duplicate. Sample found to be reactive initially by HCV Microlisa test were again tested by visual rapid test which is HCV TRI-DOT test.

\section{HCV TRI-DOT}

The $4^{\text {th }}$ Generation HCV TRI-DOT is a rapid, visual, sensitive and qualitative in vitro diagnostic test for the detection of antibodies to Hepatitis $\mathrm{C}$ Virus in human serum or plasma. They are for the putative core (structural), protease/helicase NS3 (nonstructural) NS4 (non-structural) and replicase NS5 (non-structural), regions of the virus in the form of two test dots " $\mathrm{T}_{1} " \&$ " $\mathrm{T}_{2}$ " to provide a highly sensitive and specific diagnostic test. This Kit is manufactures by $\mathrm{J}$. Mitra \& Co. Pvt. Ltd. New Delhi, India. Principle: $4^{\text {th }}$ generation HCV TRI-DOT has been developed and designed using modified $\mathrm{HCV}$ antigens representing the immune dominant regions of $\mathrm{HCV}$ antigen. $\mathrm{HCV}$ antigens are immobilized on a porous immune filtration membrane. Interpretation: - Results are noted as per manufactures guidelines and results were interpreted accordingly. If test dots $\mathrm{T}_{1}, \& \mathrm{~T}_{2}$, either both dark and light in colour (pink), result should be considered reactive for antibody to $\mathrm{HCV}$. If only control dot appear it indicates that the sample is nonreactive for anti-body to $\mathrm{HCV}$. Sample found to be positive for $\mathrm{HCV}$ antibodies by both HCV Microlisa test \& HCV TRI-DOT method would be further tested for hepatitis B Surface antigen by ELISA test.

\section{Bio-Safety}

All standard precautions, bio-safety measures $\&$ biomedical waste managements in our study according to Biological waste management's Rules 1998 were observed.

\section{Results and Discussion}

In our study, A total of 1944 blood samples were collected from the outdoor and indoor patients of Govt, Medical College, Dungarpur and its allied hospitals. Out of these, total no. of 1756 samples were tested for HBsAg and 188 samples for HCV by ELISA method (gold standard) as a confirmatory method and samples found reactive were again tested by rapid test kits. On testing for 1756 samples of HBsAg, 78 samples were reactive by ELISA but only 70 were reactive in Rapid test and Out of 188 samples for $\mathrm{HCV}, 7$ were reactive for HCV by ELISA but only6 samples were reactive by Rapid test.

Table shows that using ELISA as a gold standard confirmatory method, sensitivity of rapid card test for HBsAg was $89.74 \%$, specificity was $100 \%$, PPV(positive predictive value) was $100 \%$, NPV (negative predictive value) was $99.52 \%$, Diagnostic accuracy was 99.54\%, Youden's index was 0.897 and F1 Score was 0.945 whereas sensitivity of rapid card test for Anti HCV Antibodies was $85.71 \%$, specificity was $100 \%$, positive predictive value was $100 \%$, negative 
predictive value was $99.45 \%$, Diagnostic accuracy was $99.47 \%$, Youden's index was 0.857 and F1 Score was 0.923 .

In the present study ELISA was compared with the rapid kits for the screening of HBsAg and Anti HCV Antibodies. For HBsAg and Anti HCV Antibodies screening, rapid tests are equally sensitive to ELISA and yet they are cheaper and quicker. Within the rapid tests, the sensitivity and specificity was same but there were variations in the cost. (14) ELISA and other advanced methods are laboratory based, time consuming and require trained personnel. Rapid test enables early detection at sites where laboratory facilities or trained manpower are not available or there is issue of accessibility. $(18,19)$ The rapid tests reduce the potential for loss of follow up of a case when results are not given straight away. The high laboratory cost is another factor that reduces the willingness to screen the general population. Ideally rapid devices should have a high degree of sensitivity and a reasonable specificity so as to minimize false positive and false negative results (14) (Fig. 1 and Table 1$6)$.

Table.1 Comparative Evaluation of Rapid Test Kits with ELISA forHBsAg and Anti HCV Antibodies Tests

\begin{tabular}{|c|c|c|c|c|c|}
\hline TESTS & $\begin{array}{c}\text { Reactive } \\
\text { by } \\
\text { ELISA }\end{array}$ & $\begin{array}{c}\text { Percentage } \\
\text { Reactivity }\end{array}$ & $\begin{array}{c}\text { Reactive by } \\
\text { RAPID } \\
\text { TESTS }\end{array}$ & $\begin{array}{c}\text { Percentage } \\
\text { Reactivity }\end{array}$ & $\begin{array}{c}\text { False Negative } \\
\text { by RAPID } \\
\text { TESTS }\end{array}$ \\
\hline HBsAg & $\mathbf{7 8}$ & $4.44 \%$ & $\mathbf{7 0}$ & $\mathbf{3 . 9 8 \%}$ & $\mathbf{0 . 4 6 \%}$ \\
\hline $\begin{array}{c}\text { Anti HCV } \\
\text { Antibodies }\end{array}$ & $\mathbf{7}$ & $\mathbf{3 . 7 2 \%}$ & $\mathbf{6}$ & $\mathbf{3 . 1 9 \%}$ & $\mathbf{0 . 5 3 \%}$ \\
\hline
\end{tabular}

Table.2 Comparative Evaluation of HBsAg CARD Rapid Test Kit with HBsAg ELISA Test

\begin{tabular}{|c|c|c|}
\hline \multirow{2}{*}{ Rapid Card Test } & \multicolumn{2}{|c|}{ HBsAg } \\
\cline { 2 - 3 } & ELISA Reactive & ELISA Non Reactive \\
\hline Rapid Reactive & 70 & 0 \\
\hline Rapid Non reactive & 08 & 1678 \\
\hline Total cases & 78 & 1678 \\
\hline
\end{tabular}

$\mathrm{P}$ value $<0.001$

Table.3 Comparative Evaluation of HCV DOT Rapid Test Kit with Anti HCV Antibodies ELISA Test

\begin{tabular}{|c|c|c|}
\hline \multirow{2}{*}{ Rapid Card Test } & \multicolumn{2}{|c|}{ Anti HCV Antibodies } \\
\cline { 2 - 3 } & ELISA Reactive & $\begin{array}{c}\text { ELISA Non } \\
\text { Reactive }\end{array}$ \\
\hline Rapid Reactive & 06 & 0 \\
\hline Rapid Non reactive & 01 & 181 \\
\hline Total cases & 07 & 181 \\
\hline
\end{tabular}

$\mathrm{P}$ value $<0.001$ 
Table.4 Comparative evaluation of rapid test kits with ELISA as a gold standard confirmatory method

\begin{tabular}{|c|c|c|c|c|c|c|c|}
\hline Tests & Sensitivity & Specificity & PPV & NPV & $\begin{array}{c}\text { Diagnostic } \\
\text { effectiveness } \\
\text { (accuracy) }\end{array}$ & $\begin{array}{c}\text { Youden's } \\
\text { index }\end{array}$ & F1SCORE \\
\hline $\begin{array}{c}\text { HBsAg by } \\
\text { Rapid card } \\
\text { test }\end{array}$ & $\mathbf{8 9 . 7 4 \%}$ & $100 \%$ & $100 \%$ & $99.52 \%$ & $99.54 \%$ & 0.897 & 0.945 \\
\hline $\begin{array}{c}\text { Anti HCV } \\
\text { Antibodies by } \\
\text { Rapid card } \\
\text { test }\end{array}$ & $\mathbf{8 5 . 7 1 \%}$ & $100 \%$ & $100 \%$ & $99.45 \%$ & $99.47 \%$ & 0.857 & 0.923 \\
\hline
\end{tabular}

*Sensitivity (also called the true positive rate, the recall, power, hit rate or probability of detection)-refers to a test's ability to designate an individual with disease as positive.

Specificity (also called the true negative rate or selectivity)-refers to a test's ability to designate an individual who does not have a disease as negative.

Positive predictive value (PPV also called the precision)-is the ability of an assay to identify actual infected individuals among all persons.

Negative predictive value (NPV)-is the ability of an assay to identify correctly the real non-infected individuals among persons.

Diagnostic accuracy (DA also called the Diagnostic effectiveness)-The accuracy of a test is its ability to differentiate the patient and healthy cases correctly. DA is affected by disease prevalence.

Youden's index (also called Yuoden J satstices)-It is a single statistic that captures the performance of a dichotomous diagnostic test. DA is affected by spectrum of disease, not by disease prevalence

F1Score-(also called theaka F-Score/F-Measure)-It is the harmonic mean (average) of the PPV and Sensitivity. It can be used as a single measure of performance of the test for the positive class.

Table.5 Comparison of Rapid Test and ELISA for HBsAg in other studies

\begin{tabular}{|l|l|l|l|}
\hline Author & Place & HBsAg & \\
\hline & $\begin{array}{l}\text { Positive by Rapid } \\
\text { test }\end{array}$ & Positive by ELISA \\
\hline Ijaj H et al., 2012 (6) & Pakistan & 95 & 100 \\
\hline $\begin{array}{l}\text { Adeyemi AA et al., } \\
\text { 2013 (1) }\end{array}$ & Nigeria & 38 & 71 \\
\hline $\begin{array}{l}\text { EWS Chameera } \text { et al., } \\
\text { 2015 (4) }\end{array}$ & Srilanka & 04 & 05 \\
\hline $\begin{array}{l}\text { Mohammad K } \text { et al., } \\
\text { 2016 (12) }\end{array}$ & India (Haryana) & 22 & 30 \\
\hline $\begin{array}{l}\text { Parth R } \text { et al., 2016 } \\
(13)\end{array}$ & India (Guajrat) & 70 & 80 \\
\hline Present study (2019) & India(Dungarpur) & 70 & 78 \\
\hline
\end{tabular}


Table.6 Comparison of rapid test and ELISA for Anti HCV antibodies in other studies

\begin{tabular}{|l|l|l|l|}
\hline Author & Place & Anti HCV Antibodies \\
\hline & $\begin{array}{l}\text { Positive by Rapid } \\
\text { test }\end{array}$ & Positive by ELISA \\
\hline $\begin{array}{l}\text { Ijaj H } \text { et al., 2012 (6) } \\
\begin{array}{l}\text { Adeyemi AA et al., } \\
2013(1)\end{array}\end{array}$ & Pakistan & 07 & 12 \\
\hline $\begin{array}{l}\text { Mohammad K et al., } \\
\text { 2016 (12) }\end{array}$ & India (Haryana) & 00 & 04 \\
\hline Present study (2019) & India(Dungarpur) & 6 & 100 \\
\hline
\end{tabular}

Fig.1 Comparative evaluation of Rapid Test Kits with ELISA for HBsAg and Anti HCV antibodies test

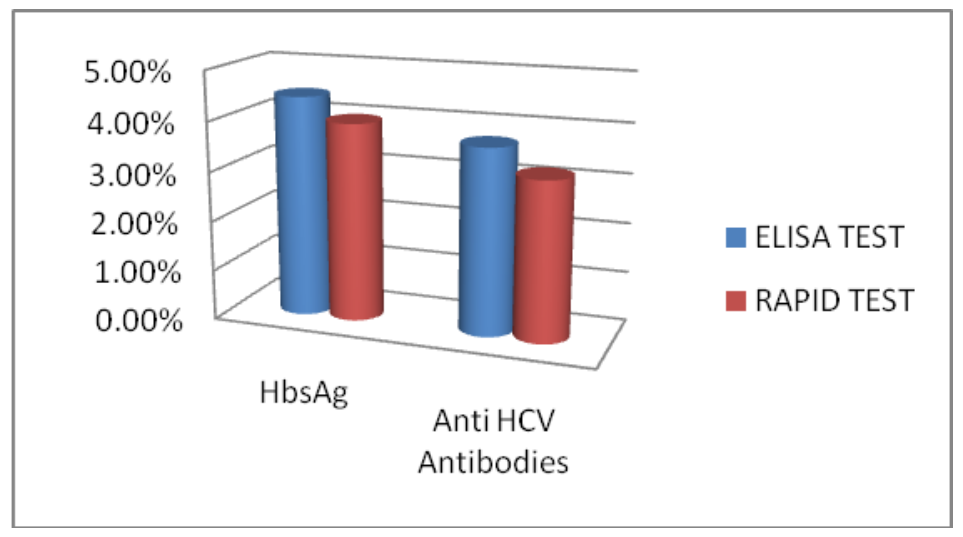

This study agrees with previous studies in other countries, which have stated that rapid test kits are not sensitive enough to be used solely for the detection of HBsAg and HCV. $(9,18)$ Some studies suggest that the diagnostic performance of Rapid Test is comparable to ELISA. However in our study we found ELISA to be much more sensitive than Rapid Test. The our results were correlated with the Previous studies byljaj $\mathrm{H}$ et al., 2012 (Pakistan) $^{6}$, Adeyemi AA et al., 2013 (Nigeria) $^{1}$, EWS Chameera et al., 2015 (Srilanka) ${ }^{4}$, Mohammad K et al., 2016 (India) $^{12}$ and Parth R et al., 2016(India) ${ }^{13}$. The results were also correlated with the other studies by Kaur et al., $(2000)^{8}$, Raj et al., $(2001)^{15}$, Zahoorullah et al., (2001) ${ }^{21}$, Lin et al., $(2008)^{10}$ and Khan et al., (2010) ${ }^{9}$. Comparison of studies conducted by other researchers showed slight variations in results. Results were varies with geographical distribution and social characteristic of population groups. Our study is a step ahead in this direction with the purpose of providing authentic scientific data based on the affected population. We conclude that $\mathrm{HBV}$ and $\mathrm{HCV}$ directly affects epidemiology, morbidity, mortality, socioeconomic and preventive aspects, So particularly in developing countries like India, the present study and other similar studies by early detection of viral prevalence for in assessment of disease burden in community and in controlling the complications of $\mathrm{HBV}$ and $\mathrm{HCV}$ viral infections.

The ultimate goal of this study was to recommend most reliable and cost-effective 
rapid kits for the diagnosis of $\mathrm{HBV}$ in areas where advance diagnostic facilities are not available. We reported that rapid test is less efficient than ELISA compared with conventional ELISA which needs long time, Rapid card test results are available within minutes. This will be very helpful in initiating immediate treatment and minimizing the serious complications and mortality. Conventional ELISA cannot be performed for single or small number of samples, since it would be quite uneconomical. Hence, they are used for testing of large samples. Rapid card test are quite susceptible to unfavourable storage conditions, so this is essential to do periodic quality control checks to avoid false positive or false negative results. These rapid card tests should be recommended only in resource limited poor settings, remote areas and peripheral health facilities for screening purpose. HBV and $\mathrm{HCV}$ are highly dangerous infection for community; false negative results leave a threat of silent transmission and spreading of diseases among people and also create an urge for more sensitive assays such as ELISA. A major concern in utilizing rapid screening tests is that these tests should have a high degree of sensitivity and a reasonable level of specificity to minimize false positive and false negative results. HBV and $\mathrm{HCV}$ are highly dangerous infection for community; false negative results leave a threat of silent transmission and spreading of diseases among people and also create an urge for more sensitive assays such as ELISA. Therefore, it is recommended that, rapid test kit should be used in conjunction with other immunoassay particularly ELISA technique.

\section{References}

1. Adeyemi AA, Omolade OA, RaheemAdemola RR (2013) Immunochromatographic Testing Method for Hepatitis B, C in Blood
Donors. J Antivir Antiretrovir S3. doi 10.4172/ jaa.S3-005

2. Allain JP, Lee H. Rapid tests for detection of viral markers in blood transfusion. Expert Rev MolDiagn. 2005; 5: 31-41p.

3. Caypers, H.T.M. Wiakel, I.N. Vander Poel, C.L. et al., (1971) J. of Hepatology, 13, 5.15.

4. EWS Chameera, $\mathrm{F}$ Noordeen, $\mathrm{H}$ Pandithasundara et al., (2013) Diagnostic efficacy of rapid assays used for detection of hepatitis B virus surface antigen. Srilankan journal of infectious disease $2013 \mathrm{Vol}: 3(2)$; 21-27

5. Halfon, P. etal (1997) J. Medical Virology. 52:391-395.

6. IjazHayder, Waquaruddin A, Sayed E. comparison of different ICT kits for HBsAg\& Anti HCV using gold standard ELISA. Pak J Med Res; vol. 51, No.3, 2012

7. Irwig L, Bossuyt $\mathrm{P}$, Glasziou $\mathrm{P}$, et al., Designing studies to ensure that estimates of test accuracy are transferable. BMJ.2002; 324: 669-71p.

8. Kaur H, Dhanao J, Oberoi A. Evaluation of rapid kits for detection of $\mathrm{HIV}, \mathrm{HBsAg}$ and $\mathrm{HCV}$ infections. Ind $\mathrm{J}$ Med Sci. 2000; 54: 432-4p.

9. Khan JK, Lone DS, Hameed A, etal.Evaluation of the performance of two rapid immunochromatographic tests for detection of $\mathrm{HBsAg}$ and anti $\mathrm{HCV}$ antibody using ELISA tested samples. Annals of King Edward Medical University. 2010; 16(S1): 84-7p.

10. Lin Y, Wang Y, Loua A, et al., Evaluation of a new hepatitis B virus surface antigen rapid test with improved sensitivity. J ClinMicrobiol.2008; 46: 3319-24p.

11. Maity S, Nandi S, Biswas S, Sadhukhan SK, Saha MK. Performance and diagnostic usefulness of commercially available enzyme linked 
immunosorbent assay and rapid kits for detection of HIV, $\mathrm{HBV}$ and $\mathrm{HCV}$ in India. Virology journal. 2012 Nov 26; 9(1):290.

12. Mohammd Khalid Farooqui.2016 Haryana. Comparison between Rapid Immuno Chromatographic Device Test, And Elisa in Detection of Hbsag and Anti-HCV Antibodies. Int J Recent Sci Res. 7(2,) pp. 9129-2132

13. Parth R, Goswami, Bhavin B et al., (2016), Bhavnagar, Gujarat. A study on effectiveness of rapid diagnostic test as compared to ELISA for HBsAg detection at blood bank in tertiary care hospital. Scholars Journal of Applied Medical Science. DOI: 10.21276/sjams. 2016

14. Rahman M, Khan SA, LodhiY Unconfirmed reactive screening tests and their impact on donor management. Pak J Med Sci. 2008; 24: 517-19p.

15. Raj AA, Subramaniam T, Raghuraman $\mathrm{S}$, et al., Evaluation of an indigenously manufactured rapid immunochromatographic test for detection of HBsAg. Ind $J$ Pathol. Microbiol. 2001; 44: 413-14p.

16. Sarin, S.K. and Hess. G. (1998). Transfusion associated Hepatitis.

17. Sayers, M.H. and Gretch D.R. (1993). J. Transfusion 30,809-13.
18. SreedharBabu KV, Chaitanya Kumar IS, Yashovarhan A, ureshBabu B, Verma A, et al., (2012) Evaluation of Immunochromatographic and ELISA methods in detection of Anti HCV Antibodies among Healthy Blood Donors; a Pilot Study. J ClinSci Res 110-111.

19. World Health Organisation: Advance in Viral Hepatitis, Technical Report Series No. 602 (1977), Geneva. Voller A., Bidwell D.E. and Barriett A: The enzyme linked immunosorbent Assay(ELISA), Dynatech Europe: Borough House, Ru du pre, Guernsey, G.B. (1979)

20. World Health Organization. Status of blood safety in the WHO African Region. Report of the 2004 Survey WHO Regional Office for Africa, Brazzaville. Geneva: WHO; 2007.

21. Zahoorullah, Akhtar T, NajibulHaq, et al., Latex agglutination and immunochromatographic screening tests verses reverse passive hemagglutination for $\mathrm{B}$ surface antigen in serum. Pakistan Journal of Medical Research.2001; 40: 69-71p.

22. Zuckerman A. J. and Howard C.J.: Hepatitis Viruses of Man, Academic Press London, (1980).

\section{How to cite this article:}

Bhupendra Kumar Mandawat and Vipul Mathur. 2019. A Comparative Evaluation for Detection of Hepatitis B Surface Antigen and Anti HCV Antibodies by Rapid Diagnostic Tests and ELISA Method at Govt. Medical College, Dungarpur, India. Int.J.Curr.Microbiol.App.Sci. 8(07): 1835-1843. doi: https://doi.org/10.20546/ijcmas.2019.807.218 